\title{
Requirement Analysis on Cement Enterprise Comprehensive Information System
}

\author{
Fengxia Cong ${ }^{1, a}$, Guijiao Wang ${ }^{2, b}$, Chunqiang $\mathrm{Li}^{3, \mathrm{C}}$ \\ ${ }^{1}$ College of Foreign Languages, Bohai University, Jinzhou, 121013, China \\ ${ }^{2}$ Department of Finance, Bohai University, Jinzhou, 121013, China \\ ${ }^{3}$ School of Information Management, Beijing Information Science and Technology University, \\ Beijing, 100101, China \\ ajzcfx1972@tom.com, ${ }^{b} 172940417 @ q q . c o m,{ }^{c} 642510571 @ q q . c o m$
}

Keywords: cement enterprise; comprehensive information system; requirement analysis; contract management; out warehouse management; equipment management; product management

\begin{abstract}
Cement is one of the basic raw materials of the national economy, and it has become a very important and difficult to replace building materials in the construction field. The computer software system in most of the cement companies exist function of the management system relatively simple, data sharing ability and poor security, the problem of man-machine dialogue maneuverability, informationization level can not meet the need of advanced production technology. Through the investigation of cement enterprises, analyses the demand of the integrated information system of cement enterprises, the overall concept of software function and performance, describes as specific software requirements specification, so as to lay the foundation for software development. The system closely combines all the resources of the enterprise with the management system, in order to achieve the goal of coordinating the use of resources and improve the economic efficiency.
\end{abstract}

\section{Introduction}

Information system is composed of computer hardware, network and communication equipment, computer software, information resources, information users and rules and regulations to deal with information flow for the purpose of man-machine integration system. The main task of constructing the information system of the enterprise is to maximize the use of modern computer and network communication technology to strengthen enterprise information management, through the investigation of the enterprise of human, material and financial resources, equipment and technology resources, establish the correct data, processing and prepare a variety of information, provide to management in time, in order to make the right decisions, and constantly improve the management level of enterprises and economic benefits.

The five basic functions of information system are input, storage, processing, output and control. Among them, the input function, purpose and system depends on the system to achieve the ability and information environment permission; storage function, ability of the system to store all kinds of information and data; processing, OLAP and data mining technology based on data warehouse; output function, various functions of information system is to ensure that ultimately the best output function. Control function, to constitute the system of various information processing equipment for control and management of the entire information processing, processing, transmission and output and other links through a variety of procedures to control.

As a traditional industry, building materials industry, has long been known as the "two high and one resour" industry, is only third of large energy consumption to metallurgy and chemical industry, so cement unit product energy consumption has an important role in building materials industry energy saving and consumption reduction. Due to the accelerated pace of new rural construction, the rapid development of the transportation industry and other factors, the demand for cement showed an increasing trend. Under the support of the national industrial policy, the highly fragmented China cement industry is about to usher in the era of restructuring and integration. 
China will focus on supporting the advantages of enterprises in the cement industry mergers and acquisitions of backward and difficult enterprises, to encourage joint restructuring of large enterprises, improve industrial concentration and resource utilization.

Cement production enterprise integrated monitoring system, automatic control system and enterprise management system, is the current development trend of cement enterprise informatization, will play a major role in realizing the cement enterprises, high yield and high efficiency to ensure production safety and improve the management level. With the development of information technology, the development trend of cement enterprise management from single application to comprehensive integration is the development trend. In order to promote the development of cement enterprises, solve the existing process of informatization construction in cement enterprises, especially the increasingly serious problem of information island, the production safety monitoring, production scheduling and management data in enterprise LAN integration and sharing, the development of the comprehensive information system suitable for the modern management of cement enterprises.

\section{Contract Management Subsystem}

Contract is an agreement between the parties or parties to establish, change or terminate the civil relationship. Enterprise economic transactions mainly through the form of contract. Contract management refers to the general term of a series of behaviors, such as the conclusion, performance, modification, dissolution, termination, and review, supervision and control of the enterprise's contract for the parties to the contract in accordance with the law. Perfect contract management is an important symbol of the healthy operation of enterprises. Contract management system is based on information technology, using the advanced management ideas of modern enterprise, for the enterprise to provide the decision-making, planning, control and performance evaluation of the comprehensive and systematic contract management platform.

Contract management is an important base of the whole sales management system. A contract only one settlement unit, and can only have a variety of categories; according to the contract of payment is divided into a contract and non contract for the contract clause of the contract need to strictly control the customer models available is sufficient; according to the way of delivery is divided into vehicle and zero, vehicle delivery contract by scheduling production plan, arrange departure, zero delivery contract is directly issued bills of lading, and then to the warehouse out of library, and finally open statement. The system function of the contract management process design in accordance with the contract management process design, sign, performance and ending is shown in Fig. 1.

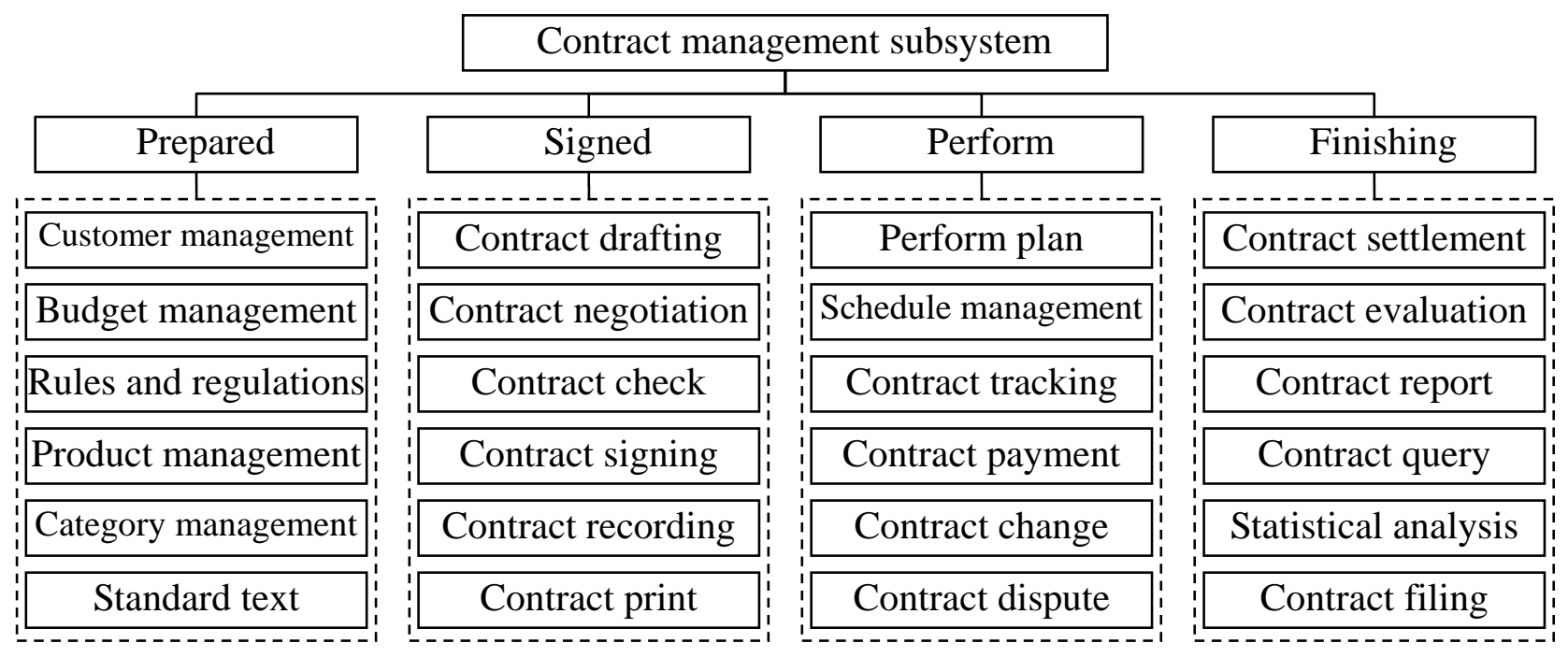

Fig. 1. Function on contract management subsystem

To support the product characteristics of the cement industry, there are some specific 
requirements: sales contract details include product brand, variety and label data; compliance with the new contract law, provide contract review records and contract change records, the required data generated by the system automatically, without human two preparation, reduce the workload of maintenance data support the goods; partial shipment of different delivery address automatic delivery, arrange delivery plan, support a variety of payment and processing a variety of means of settlement; provide electronic visa processing, all contracts to achieve multi-level audit system, timely correct the errors in the contract, to avoid loss of business, safeguard the interests of enterprises; the execution of the contract may modify, suspension and resumption of operations; provide a query to query the status of the execution of the contract, such as shipments, stock returns and customer details.

\section{Out Warehouse Management Subsystem}

Inventory management system is mainly used for inventory management, warehousing, a library and query for the main application types to establish the corresponding transaction processing, so that the quantity of goods inventory control in the best condition. System can be set according to each of the minimum inventory and the maximum inventory to display the inventory information, that is, which goods need to be put in storage, which goods have been more than the number of inventory. After that, the management department may decide the purchase or sale plan through the stock information. This is to ensure that the daily production will not because of lack of raw materials to production, to ensure smooth production, also can make the enterprise not because of the amount of raw materials and the backlog of excess inventory of enterprise liquidity, thereby enhance the economic efficiency of enterprises.

The core business of the inventory management system includes storage management and out warehouse management. A library operation process is shown in Fig. 2. Sales by the sales department issued the shipping bill, passed automatic warehouse system, simplify the daily bill transfer work; other types also support library operations, such as the internal allocation of library, inventory loss of Library and Library and other forms of conversion of goods. Effective means that the current inventory of goods to meet customer delivery orders or to the manufacturers to return a single requirement.

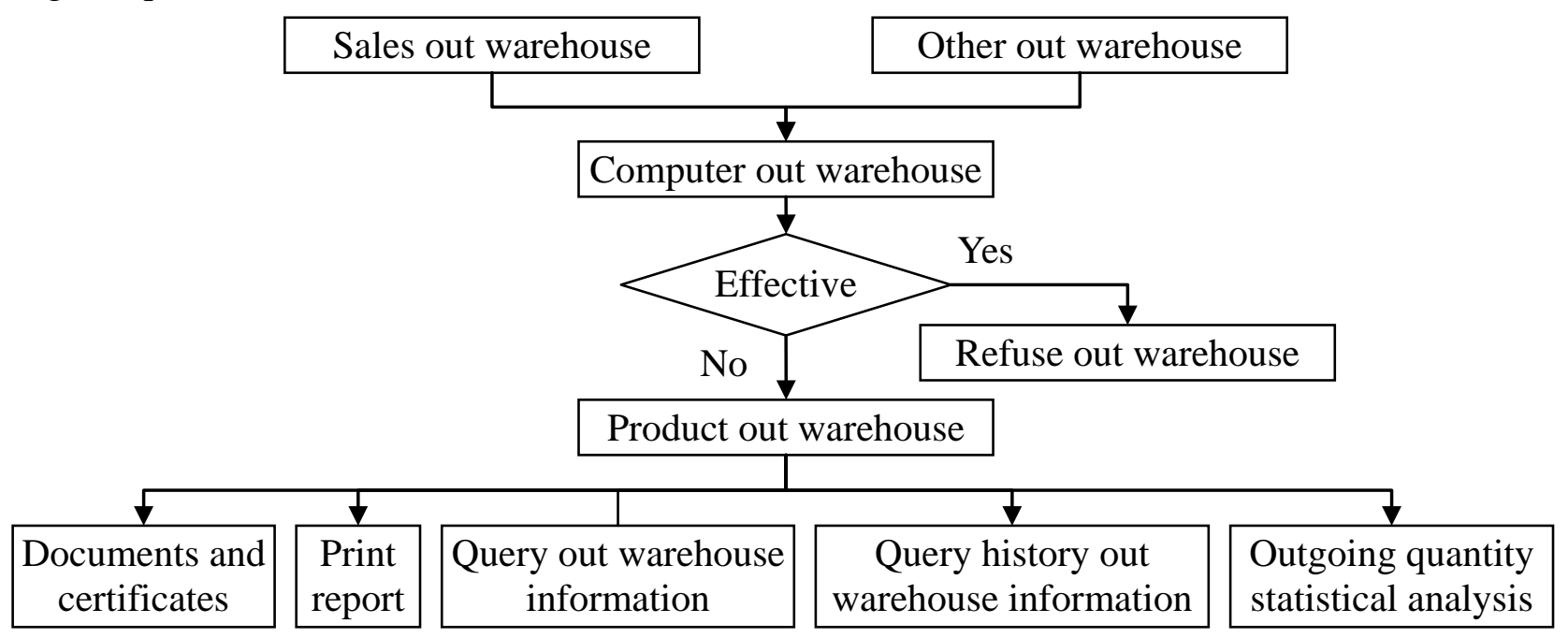

Fig. 2. Operation process on out warehouse

\section{Equipment Management Subsystem}

Cement production equipment occupies a very important position in the enterprise, how to deal comprehensively for the procurement of equipment, reduce equipment maintenance costs, improve equipment operation rate, between factory or workshop called flexible idle equipment is mainly to solve the problems of equipment management, equipment management system all production of the 
production line, equipment installation and commissioning, to record the daily operation and maintenance, maintenance, overhaul, failure and equipment related information from equipment procurement, equipment scrapped until.

(1) Equipment archives. Detailed records of equipment models, manufacturers, technical drawings, parts and components of the construction and procurement date and other technical information, provide the appropriate technical information for the maintenance of equipment. Equipment is recorded as a tree structure, the main equipment includes auxiliary equipment, auxiliary equipment, including parts.

(2) Maintenance plan. According to the annual production plan and operation of equipment, equipment overhaul plan, the plan and the monthly maintenance plan, and the plan is broken down into the task list. According to production line equipment and spare parts production equipment and spare parts purchase demand application form.

(3) Maintenance management. The maintenance and repair tasks to each of the maintenance personnel, maintenance personnel to complete the task will be related to the maintenance of information into the computer archive. Track maintenance and maintenance of the equipment, record the cause of equipment damage and the cost of maintenance, and the maintenance cost of the equipment. In addition to providing basic information of equipment maintenance personnel, and established the corresponding relationship between the equipment and maintenance personnel, according to the equipment maintenance cost, maintenance and maintenance tasks to complete the task quota for equipment maintenance staff assessment.

(4) Equipment operation monitoring. Including the operation of equipment and maintenance records, equipment, running the boot and shutdown, the operating table when the device. Equipment inspection record, equipment accident and fault record. The measuring value of the production line is classified according to the corresponding equipment, and the standard operation parameters are established for the equipment, and the alarm information database is established for each signal abnormality, which is convenient for the equipment maintenance personnel to find fault in the early stage. The statistics of each equipment running time and downtime, yield and feed etc..

\section{Product Management Subsystem}

Coding the products of portland cement, ordinary cement, slag cement, volcanic ash cement and composite cement. All item code requirements are unique, that is, the same kind of item, regardless of the product or no matter in which module, can only use the same code. In this system, the article code is the character type, the longest is 18. Cement product type, mainly used to identify the classification of cement products. Including: composite cement, Portland cement, Portland cement, Portland cement, fly ash cement, dam cement and oil well cement.

Compound cement is usually labeled as 32.5. Main ingredients: 70\% clinker, slag and gypsum tuff 32.5\%, 5\%. The clinker will be $80 \%$ limestone, iron 5\%, silicon aluminum raw material $15 \%$ temperaturefiring. Ordinary portland cement label is 42.5. Main ingredients: $82.5 \%$ clinker, slag and gypsum tuff $12.5 \%$, 5\%. The clinker will be $80 \%$ limestone, iron $5 \%$, silicon aluminum raw material $15 \%$ temperaturefiring. All cement production lines are the same, the difference is the change of the proportion of the ingredients.

The material relation table is the bill of materials, product structure is that the cement production technology and management with the form of data file, and cement factory planning, finance, supply and workshop and other departments to calculate product cost, plan the basic material supporting documents, therefore, goods related to the accuracy of the table is one of the factors that determine the running effect of the entire system the main. The structure of the material relation table is shown in Fig. 3.

The material relation table is used to establish the level of the actual use order of all the materials in the production of cement products. The relationship between the quantity and the norm of the product, the intermediate product (such as clinker) and the original fuel is established. The parent material of the upper layer, the lower sub project items. Parent project and child project are relatively speaking, usually a material is not only the sub item of the upper level, but also the parent 
item of the lower level items. For example: "clinker" is the 0 layer of A material is the final product, is the "auxiliary raw materials", "help agent" of the parent project. 1 "clinker" is the "iron raw material" and "limestone" and "Si Al materials" and "parent project, sub project of cement materials.

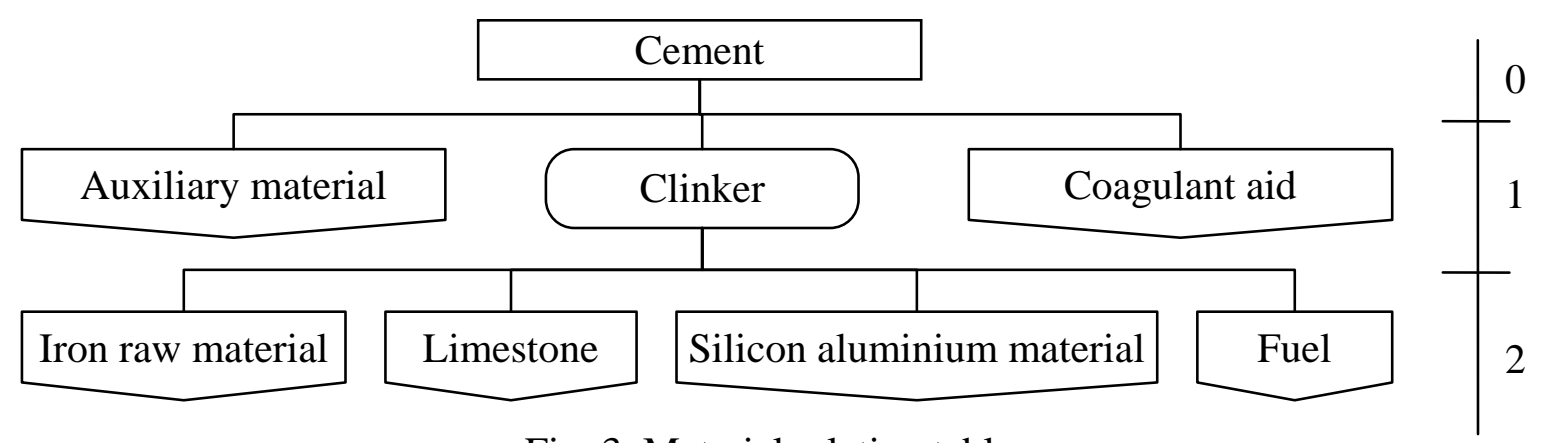

Fig. 3. Material relation table

\section{Conclusion}

The system development will be targeted at the lower level of informatization of small and medium-sized cement enterprises, combined with the whole process of cement production and sales, with the production of large scale, long process, complex process and strong continuity characteristics, taking into account the use of existing enterprise system and protect the investment of existing, and pay attention to the existing and raw materials laboratory, control system, expert system, central monitoring management system and expert system with ball mill. All the resources of enterprises through management system closely together, in order to achieve the coordinated use of resources, through the integration of the utilization efficiency of the resources to improve all aspects of business, for cement enterprises to pursue profit maximization and facing the changing market quickly and make the right decisions, provide a good solution for improving work efficiency.

\section{References}

[1] C. M. Li, H. X. Chen, Y. D. Ma, "Information solution of store management in cement enterprise," China Building Materials Science \& Technology, vol. 35, no. 5, pp. 28-32, 2013.

[2] A. Y. Dai, J. Chen, "Exploration and Research on information construction of Yunnan cement enterprises," Development Guide to Building Materials, vol. 34, no. 1, pp. 52-55, 2012.

[3] S. L. Wang, "Research and application of cement enterprise integrated information system," Master's degree of Shandong jianzhu university, 2010.

[4] J. J. Wang, L. Wang, H. S. Du, "Case introduction of production information management system for cement enterprises," China Cement, vol. 31, no. 3, pp. 61-62, 2016.

[5] Z. R. Li, X. B. Bai, "Scheme Design of the Contract Management Informatization System," Office Informatization vol. 22, no. 6, pp. 51-53, 2016.

[6] Q. Wei, "Warehouse inventory management system design and implementation analysis," Telecom Worldn, vol. 23, no. 3, pp. 236-237, 2016.

[7] Y. W. Zhang, L. J. Xie, "Realization and application of equipment management system," Technology Innovation and Application, vol. 6, no. 20, pp. 18-19, 2016. 